\title{
APONTAMENTOS PARA UMA GEOPOLÍTICA DA TRADUÇÃO NO SÉCULO XXI
}

\author{
Roberto Mulinacci* \\ Universidade de Bolonha
}

\begin{abstract}
Resumo: A partir de um retrospecto sobre a relação entre cultura e tradução, este artigo pretende chamar a atenção para os reflexos geopolíticos que se escondem por trás de uma praxe aparentemente neutra como o traduzir, tentando equacionar os problemas de uma sua nova conceituação na nossa aldeia global.
\end{abstract}

Palavras-chave: Tradução. Cultura. Geopolítica.

\section{NOTES FOR A GEOPOLITICS OF TRANSLATION IN THE TWENTY-FIRST CENTURY}

\begin{abstract}
Taking the relationship between culture and translation as a starting point, this paper focuses on the geopolitical reflexes of an apparently neutral praxis such as translating, trying to address the problems of its new conceptualization in our current global village.
\end{abstract}

Keywords: Translation. Culture. Geopolitics.

\footnotetext{
* Possui graduação e mestrado em Língua e Literatura Portuguesa pela Universidade de Florença, Itália. Doutorou-se em Literaturas Portuguesa e Brasileira pela Universidade de Bolonha, em 1998. Atualmente é professor Associado de Linguística Portuguesa e Brasileira do Dipartimento di Lingue, Letterature e Culture Moderne da Universidade de Bolonha. Bolonha, Itália. E-mail: roberto.mulinacci@unibo.it
} 
Na tentativa de abordar, ainda que de modo parcial e inevitavelmente precário, devido à sua complexidade e vastidão o tema que aqui me proponho discutir, elejo como ponto de partida um mini-percurso bibliográfico através dos textos que mais contribuiram, na minha opinião, para fornecer os balizamentos teóricos essenciais do nosso objeto de estudo, a partir de sua articulação crítica. Não pretendo - nem caberia, neste lugar - fazer um levantamento exaustivo dos muitos ensaios que fazem referência aoentrelaçamento entre cultura e tradução, mas vou mencionar apenas algumas etapas significativas das trajetórias convergentes destes dois polos conceituais, cuja integração recíproca (embora, creio, por vezes, ainda assimétrica) no palimpsesto do debate contemporâneo talvez possa ser hoje repensada mesmo em função de uma espécie de tertium comparationis, isto é, de um terceiro elemento afora os dois que estão sendo comparados e que representa, digamos assim, o horizonte de sentido da própria comparação. Refiro-me obviamente àquele paradigma geopolítico que intitula este meu artigo, sendo dele, ao mesmo tempo, o pressuposto e a meta, apesar das plausíveis dificuldades em descortiná-lo de imediato por detrás das múltiplas interações entre cultura e tradução. Vale a pena então indagar: o que cultura e tradução compartilham com a geopolítica, de forma a permitir uma permeabilidade de seus discursos? $\mathrm{Ou}$, reversamente: como os métodos de análise da geopolítica podem iluminar o relacionamento dessa dupla cultural?

É, portanto, tendo em vista essas questões que vou reler agora o encontro fatal entre cultura e tradução, um encontro destinado a marcar a história recente da tradutologia, transformando uma disciplina autônoma, embora muito nova, como os Translation Studies, em um campo de pesquisa intrinsecamente inter- e multidisciplinar. Deve-se, com efeito, a essa "virada cultural" dos estudos da tradução, consistente essencialmente na osmose epistemológica com a área variegada dos Cultural Studies (de que são parte integrante, por exemplo, os Post-Colonial Studies, donde vieram umas das reflexões mais originais e interessantes sobre o assunto em apreço), a recém-adquirida densidade semântica do nosso objeto de análise, 
isto é, a própria tradução, cuja abrangência terminológica, para usar as palavras de um estudioso italiano, beira hoje em dia quase "o entupimento informativo" (Paduano, 2004, p. 151). Não se trata tanto, evidentemente, de considerar as superfetações teóricas que dizem respeito à tradução propriamente dita - o que já não é pouca coisa -, quanto, antes, de ressaltar as inúmeras acepções que o termo tradução tem vindo a assumir ao longo destas últimas décadas, graças principalmente ao fecundo diálogo com o conceito de cultura. É justamente a isso que se refere Mary Snell Hornby quando fala em cultural turn da moderna tradutologia, ou seja, àquela fase de abertura dos estudos congêneres para a interdisciplinaridade que se dá a partir da publicação, em 1990, do volume organizado por Susan Bassnett e André Lefevere, Translation, History and Culture, no qual o contexto cultural entra prepotentemente nas equações tradutológicas dos vários ensaios ali contidos, sobretudo sob a forma de dinâmicas de poder e de identidade. Penso, entre outros, no ensaio da indiana Mahasweta Sengupta ${ }^{1}$ sobre a relação entre tradução e colonialismo ou no da norte-americana Barbara Goddard ${ }^{2}$, sobre tradução e discurso feminista, que me parecem desempenhar um papel seminal na construção de uma tradição crítica desse tipo.

Entendamo-nos: não estou afirmando que o livro de Bassnett e Lefevere represente a primeira tomada de consciência da relevância desse relacionamento entre cultura e tradução ou que as questões coloniais, bem como aquelas relativas ao gênero, façam ali sua estreia, ao menos declinadas em chave tradutiva. Sei perfeitamente que já Eugene Nida havia se dado conta do fato de as diferenças culturais serem mais problemáticas para o tradutor do que as diferenças linguísticas e o mesmo John Catford (1980, p. 22) - um dos expoentes principais da tradutologia linguística, o qual reduzia basicamente a tradução a um problema de equivalência, identificando o ato tradutório com o processo de "substituição de material textual de uma língua por material textual equivalente em outra língua",tinha reconhecido a existência de uma questão cultural no campo da tradução, não se limitando, porém, a colocá-la sob o signo da intraduzibilidade, mas resolvendo (ou, se quiserem, dissolvendo) 
a intraduzibilidade cultural como variante da intraduzibilidade linguística. Tudo isto para dizer que não quero subestimar de modo algum as contribuições provenientes da fase que poderíamos chamar de pré-história dos Translation Studies, nem, ainda menos, daquela que tem acabado se tornando diretamente responsável pela definitiva autonomização e consagração da disciplina, uma fase, esta, à qual, de resto, pertence - embora funcionando quase à guisa de um divisor de águas em relação à nova época -, um texto como The Manipulation of Literature, que é absolutamente fundamental para o desenvolvimento dos estudos da tradução nessa direção culturalista.

É, com efeito, nesse texto de 1985, organizado por Theo Hermans e no qual se encontram alguns dos ensaístas mais representativos daquela nouvelle vague tradutológica que iria dominar a cena contemporânea - entre os quais, gosto de mencionar aqui, ao lado de Bassnett e Lefevere, Gideon Toury, Maria Timoczko e José Lambert -, é nesse texto, justamente, que, através da teoria polissistémica de Even-Zohar, a tradução se resgata de sua marginalização secular, chegando a se instalar no centro do sistema literário da cultura receptora, enquanto parte da rede de relações que liga os textos traduzidos aos textos originais engendrados naquele específico contexto cultural. Daí surgem, então, no meu entender, duas consequências importantes - e sob certos aspectos até complementares - para o pensamento crítico sobre a tradução (considerada sempre, claro, pelo ângulo da cultura): a primeira concerne precisamente à questão desse sistema cultural complexo, rotulado de polissistema, do qual a tradução participa e que, portanto, faz com que ela tenha de se adequar às normas e convenções inerentes a tal contexto de recepção (em outras palavras, são as características particulares do polissistema que condicionam as modalidades de realização de uma tradução); a segunda consequência, ao contrário, tem a ver stricto sensu com o título do livro em pauta, ou seja, a manipulação da literatura. Neste sentido, a tradução se configura como uma prática cultural que ultrapassa a mera dimensão linguística e estética do texto literário, se tornando funcional "à ideologia do tradutor e à poética imperante na literatura de chegada 
no momento em que a tradução está sendo realizada" (Lefevere 1998, p. 16). Mas, então, se, realmente, traduzir equivale a manipular a literatura, o que é que isso significa, em concreto, senão que a tradução, longe de ser uma inocente forma de espelhamento das literaturas alheias, contribui, antes de tudo, para a construção delas, isto é, para moldar as representações das várias literaturas (e, mais em geral, das várias culturas) espalhadas mundo afora? É esta, me parece, a implicação mais fecunda que traz a reflexão dos estudiosos da Manipulation School.

De resto, sabe-se muito bem que o número das traduções procedentes de um determinado país, a seleção dos textos dele a serem traduzidos, as estratégias tradutórias para isso adotadas, são todas variáveis que não só dependem da cultura de chegada, como também incidem profundamente na imagem que ali se constrói da cultura de partida. Portanto, além de refletirem as exigências de representação e os critérios de inteligibilidade da literatura traduzente, as traduções participam também da construção da identidade cultural da literatura traduzida, na medida em que, por exemplo, elas definem inclusive uma espécie de cânone da literatura estrangeira naquele particular contexto de recepção. $\mathrm{Na}$ verdade, conforme nos tem explicado muito bem Lawrence Venuti (2002, pp. 195-196), pouco importa que esse cânone não passe de uma representação apenas local do sistema literário alienígena, ou seja, de um cânone no fundo mais representativo da target culture - a saber: dos estereótipos, das idiossincrasias, da ideologia nela dominantes - do que da literatura supostamente ali representada. Pouco importa porque esse discurso canonizador da tradução, fruto de uma visão parcial e por vezes distorcida das literaturas estrangeiras, termina todavia por influenciar pesadamente a percepção que os leitores do texto alvo têm da source culture, conferindo a ela uma identidade acessória tida, porém, como primária e verdadeira. A tal propósito, Venuti (Ibidem, pp. 202-203) chama a atenção para o famoso estudo de caso do cânone da literatura japonesa nos Estados Unidos, um cânone construído basicamente pelas escolhas seletivas de um pequeno grupo de 
especialistas universitários daquela disciplina e das editoras com que eles colaboravam.

Pois bem, com referência quase à mesma época indicada por Venuti, isto é, entre os anos Cinquenta e Sessenta do século passado, para dar um exemplo que eu conheço um pouco melhor, uma coisa análoga tem acontecido com a representação italiana da literatura brasileira, que, depois das precoces traduções dos grandes romances machadianos, todas levadas a cabo já no final da segunda década, foi entregue ao exotismo mais misterioso e ameaçador, condensado, aliás, emblematicamente na versão d'Os Sertões de Euclides, publicada em 1953 com o título significativo de Brasile ignoto. Com efeito, pertencem a tal vertente - que não corresponde ao exotismo luxuriante de muita cultura brasileira de exportação, mas sim ao fascínio exercido, em toda Europa, por um mundo remoto e primitivo -, tanto o sertão selvagem e violento de Guimarães Rosa quanto o Nordeste decadente e degradado de Lins do Rego e de Graciliano Ramos. E será justamente com o Nordeste que se vai identificar, no imaginário italiano não só da época em apreço, a imagem do Brasil, embora ao retrato épico ou mítico do cenário nordestino das origens tenha vindo progressivamente a se superpor a representação pitoresca e sensual da Bahia de Jorge Amado, sem dúvida o escritor brasileiro mais traduzido na minha língua e cuja obra - da qual se empreendeu a tradução a partir de 1949 - é possivelmente uma das principais responsáveis pela estereotipização da identidade cultural do Brasil na Itália.

Felizmente, como nos ensina a crítica pós-estruturalista, "as identidades culturais são lugares semióticos de identificação resultantes de estratégias enunciativas situadas na história e nas práticas da cultura. Não se está falando, portanto, de uma essência, mas sim de um simples posicionamento em relação a pontos de referência sempre diferentes" (Demaria 2002, p. 121), o que determina o caráter absolutamente dinâmico e contextual dessas identidades, sujeitas à força das várias representações. Daí resulta que a imagem de uma literatura nunca é fixa e então pode mudar se mudarem também as construções discursivas que se encontram na base de 
seu processo de canonização no interior das outras culturas. Assim, se se mudar o conjunto dos textos selecionados para a tradução ou se a própria tradução conseguir se libertar dos vínculos poéticos e ideológicos impostos pelo sistema receptor, vai se transformar também o cânone da literatura traduzida, como demonstra justamente a situação do mercado editorial italiano, onde, ao longo das últimas décadas, o leque de autores e textos brasileiros disponível se tem ampliado muito, oferecendo um panorama bastante representativo da produção literária do Brasil, quer do ponto de vista quantitativo (o número total das traduções), quer do ponto de vista qualitativo (no que diz respeito principalmente a uma maior diversificação temática, incluindo, por exemplo, aqueles escritores urbanos anteriormente negligenciados em função mesmo de uma imagem rural do Brasil, "o que - como escreve Márcia A.P. Martins (2008, p. 51) - poderá ajudar a desconstruir as representações redutoras e estereotipadas": tanto para dar uma ideia, com referência à reportagem promovida em 1994 pela revista Veja, dos 22 livros incluídos no cânone brasileiro pelos maiores intelectuais do país, 15 estão traduzidos em italiano, o que me parece afinal uma boa porcentagem.

Seja como for, independentemente da fisionomia do caso específico, o que cabe aqui sublinhar é, em particular, o papel desempenhado, nessa construção do cânone, por aquele mecanismo de controle, denominado patronagem (o copyright dessa denominação pertence mais uma vez a Lefevere), "que regula o sistema literário de dentro das estruturas socioeconômicas e ideológicas da sociedade" (Martins 2008, p. 44). São estes, enfim, para continuar a citação, "os centros de poder (pessoas ou instituições) - aqui na acepção foucaultiana do termo "poder", isto é, enquanto força produtiva ao invés de repressiva -, que auxiliam ou impedem a escrita, a leitura ou a reescrita da literatura" (LEFEVERE apud MARTINS, 2008, p. 44), fazendo assim da tradução uma prática intimamente política. Não é por acaso que, aproveitando tal intuição das relações de poder incorporadas à materialidade do texto traduzido, o livro de Bassnett e Lefevere supramencionado levava 
mais adiante a "virada cultural" dos Translation Studies, não se limitando a deslocar o eixo do debate teórico do texto para o contexto cultural em que a tradução se insere, como também marcando a passagem de uma noção antropológica de cultura (no sentido "essencialista" da antropologia tradicional, segundo a qual a cultura consiste em um conjunto de saberes, tradições, hábitos, instituições que definem uma determinada comunidade) para uma dessubstanciação e, digamos assim, uma liberalização do conceito, com as culturas (rigorosamente no plural) que deixam de serem concebidas como meros epifenômenos de formações discursivas, tornando-se ao contrário portadoras de dinâmicas de poder, a respeito das quais cabe à tradução uma tarefa fundamental de negociação.

Dito de outro modo: a cultura já não pode ser pensada como uma entidade estática e sim como um processo dinâmico, constitutivamente aberto e intrinsecamente relacional, onde se confrontam diversas ideologias e representações que a tradução reflete e, ao mesmo tempo, contribui para criar, consolidar ou transformar. Mas se as substâncias culturais não existem enquanto correlatos ontológicos, impossibilitando a correspondência biunívoca entre indivíduos e comunidades e portanto inviabilizando também aquela identificação diferencial que preside tradicionalmente ao uso do verbete cultura (enquanto espaço da diversidade humana), isso não significa que a diferença desapareça do horizonte contemporâneo das culturas, sendo antes a responsabilidade dela transferido para as novas entidades envolvidas nesse discurso teórico, entre as quais, as questões tais como o gênero, a classe, a etnia, o poder, que são sem dúvida fatores relativizantes, embora não identifiquem de modo unívoco uma comunidade humana. Por conseguinte, a imagem de uma cultura não é apenas o resultado de uma manipulação simbólica ou de um processo de textualização ligados à prática tradutória, mas assenta também nas assimetrias do relacionamento intercultural, que são justamente um efeito das diversas posições ocupadas pelas várias culturas no cenário internacional.

Com referência, mais uma vez, à situação da cultura brasileira na Itália, por exemplo, é inegável que a anterior marginalidade do 
Brasil no sistema mundo tem explicado, durante muito tempo, o desinteresse dos leitores italianos pelos produtos culturais desse país, dando conta, além do baixo número de traduções e da pouca visibilidade da maioria delas, também das escolhas dos textos a serem traduzidos, os quais, de um lado, deviam corresponder aos estereótipos daquele específico horizonte de expectativa e, de outro lado, serviam para confirmá-los e reforçá-los, aprisionando assim a identidade cultural brasileira dentro de um imaginário cada vez mais estereotipado (a tal propósito, abrindo um parêntese, acho que seria da maior importância, pesquisar o quanto as representações de uma cultura no exterior podem influir também na percepção interna, ou seja, nacional, daquela mesma cultura - cfr. a reportagem da Veja -, levando inclusive à produção de textos culturalmente reconhecíveis, pensados para a exportação). Invertendo a perspectiva de análise, então, como se vê, os vínculos extratextuais incidem, não menos do que os textuais, nos processos tradutivos, de forma a configurar a tradução - em termos topológicos - como uma prática cultural se movendo essencialmente em um plano vertical em vez de horizontal. Basta pensar, por exemplo, nas diversas repercussões sofridas pelas estratégias tradutivas no âmbito das culturas centrais ou periféricas, dado que - usando as categorias de Gideon Toury - as primeiras (as culturas do centro) tendem a privilegiar o critério de "aceitabilidade", fazendo com que a tradução adote as normas da cultura alvo a fim de ser integrada nela, enquanto as culturas da periferia optam, em geral, pela predominância, na tradução, de um critério de "adequação" ao sistema de origem, ainda mais quando se tratar de textos oriundos dos sistemas centrais, cujo maior prestígio, que desempenha também uma função modelar para essas culturas, se revela a melhor garantia contra cada tentação de homologá-los ao contexto.

Em suma, é exatamente tal irrupção de uma visão mais dialética das culturas - a qual estava, mutatis mutandis, já presente também na teoria polissistêmica (com a distinção entre sistemas primários e secundários) -, que se responsabiliza pela "explosão" (Nergaard, 2009, p. 481) teórica e - como veremos - até geográfica da 
tradutologia nos anos Noventa do século passado, chegando inclusive a questionar aquela espécie de postulado, implícito em toda a história europeia da tradução, segundo o qual entre as várias áreas linguísticas e culturais existiriam relações paritárias e não, como é, ao contrário, sobejamente evidente, relações hierárquicas, desmentindo assim aquela utopia de um diálogo entre iguais que realmente não faz sentido se olharmos a questão de um ponto de vista, por exemplo, feminista ou pós-colonial. De fato, Translation, History and Culture é o primeiro livro do filão dos Translation Studies que, se afastando da tradição europeia "humanista" e "universalista", relaciona o discurso da tradução quer com a categoria de "gênero" quer com o colonialismo (Cf.. Nergaard, 2009, pp. 489-90), sendo, no fundo, ambas as abordagens, parte integrante de uma reflexão mais ampla que gira em torno do problema capital da subalternidade, aliás já brilhantemente equacionado, em 1988, por Gayatri Spivak em seu célebre ensaio, Can the subaltern speak?.

Ora, aplicando à tradução o raciocínio desenvolvido, na esteira do pensamento de Gramsci, pela estudiosa bengalesa sobre a impossibilidade de fala do subalterno, parece bastante óbvio o paralelismo entre a autorepresentação falhada do sujeito colonizado, cujo ato de discurso (speech act) não encontra acolhida no paradigma representacional da cultura hegemônica, redundando assim no silêncio, e a representação do subalterno levada a cabo, ao contrário, pelo intelectual pós-colonial, quase uma forma de tradução que, na tentativa de dar voz a quem não pode falar e pretendendo até falar por ele, termina simplesmente por reproduzir o mesmo silêncio, condenando o subalterno a ser apenas objeto (e não sujeito) de palavra. É esta a "violência epistêmica" do colonialismo enquanto "evento discursivo" - além de sistema socioeconômico e de ideologia - de que se faz cúmplice a tradução, não só silenciando o subalterno, mas fornecendo também o filtro ideológico através do qual ele se torna culturalmente legível aos olhos do colonizador. Destarte, ao nivelar o pluralismo e a polilogia das culturas dominadas dentro de uma representação absolutamente monológica e até monologante (ou seja, irredutível ao diálogo com o Outro), 
a tradução se revela - na opinião de Bassnett e Trivedi (1999, p. 6) - um poderoso "meio de afirmação da supremacia das culturas dominantes” (1999, p. 6), isto é, daquele Ocidente que, até há pouco, era praticamente o único detentor do poder da palavra. Vou retomar depois essa questão, mas, por enquanto, é claro que ressoa aqui, nas entrelinhas, a lição de Said e de seu Orientalismo, um dos textos fundadores da área dos Post-colonial Studies, o qual tem o mérito, entre muitos outros, de ter denunciado a retórica das configurações discursivas que formam a imagem das culturas colonizadas, plasmando-a conforme os interesses, os valores, os preconceitos da dominação colonialista. No caso específico, a invenção do Oriente como espaço imaginário contraposto ao Ocidente, que o tem reificado e ressemanticizado com o concurso fundamental justamente do orientalismo (vale dizer, daquele conjunto de disciplinas nascidas nas universidades ocidentais e relativas a esse campo de estudo), tal invenção do Oriente, dizia, não passa, no fundo, de um processo de tradução, visando com-preender e, sobretudo, reescrever o Oriente para encaixá-lo no quadro dos sistemas significantes controlados pelo discurso imperialista (sob esse aspecto, de resto, gosto de ressaltar que a crítica, tal como a tradução, figura entre as formas de reescrita listadas por Lefevere, isto é, pertence à mesma categoria das práticas manipulatórias).

Não surpreende, pois, que do Orientalismo de Said derive uma genealogia crítica sobre a relação entre cultura e imperialismo (título, aliás, de outro grande livro do intelectual palestino) que abrange todos os setores dos estudos pós-coloniais e que se revela particularmente produtiva - pelo menos no que diz respeito às questões tradutológicas - nos representantes de seu ramo "oriental", ou melhor, lato sensu não-ocidental, portadores de uma experiência concreta e historicamente determinada da condição colonial. Com efeito, uma das novidades maiores introduzidas pelo cultural turn dos anos Noventa consiste, sem dúvida, no alargamento não só das fronteiras disciplinares do setor, através do contributo das demais ciências humanas (antropologia, sociologia, psicanálise, etc.), como também no alargamento de suas fronteiras propriamente geo- 
gráficas, incluindo pela primeira vez estudiosos dos países normalmente submetidos a esse tipo de olhar. Além de Sengupta, a quem me referi no início deste artigo por ser ela a chefe-de-fila de tal vanguarda extra-ocidental, penso também em Tejaswini Niranjana, autora de vários ensaios e de um livro importante acerca do tema em pauta como Siting Translation: History, Poststructuralism and the Colonial Context de 1992 e, ainda mais, em Harish Trivedi, talvez um dos nomes mais conhecidos dentre os que compartilham abordagens semelhantes, graças também a uma afortunada parceria editorial com Susan Bassnett, donde saiu em 1999 o volume Postcolonial Translation. Theory and practice.

Trata-se de autores, estes, cujo advento no mapa mundial dos estudos da tradução se tem provado decisivo para a ruptura do paradigma eurocêntrico até então ali dominante, vindo propor, ao lado de uma revisão de alguns conceitos operacionais (in primis, o de tradução), também uma nova epistemologia das representações do Outro, a partir justamente do desvendamento do potencial político nelas contido. De fato, reduzida a "significant technology of colonial domination", como a definiu Niranjana (1992, p. 21) ou transformada em um instrumento de resgate e de resistência capaz de contribuir - de modo igualmente significativo - aos processos de descolonização, a tradução vista pelo prisma dos Postcolonial Studies carrega, pois, o peso de uma política cultural diretamente implicada na releitura e reescrita da História. O que, conforme ressalta em um belo ensaio o próprio Trivedi (2009, p. 150), não pressupõe necessariamente a vontade de "fundir ou confundir a tradução com o colonialismo", mas apenas de tentar "ler uma à luz do outro, a fim de adquirir um maior conhecimento da his-

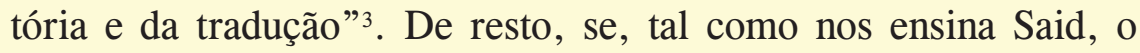
colonialismo é uma experiência comum a colonizadores e colonizados, uma vez que ambos introjetaram as mesmas estruturas mentais para a definição da identidade em relação à alteridade, esta polinização dos Translation Studies da parte da teoria pós-colonial não se restringe às pesquisas realizadas fora do Ocidente nem às relações interculturais entre "Primeiro" e "Terceiro Mundo" - se é 
que continua sendo plausível o uso de certos rótulos, que eu tomo emprestados do belo volume de Dingwaney e Maier ${ }^{4}$, para indicar a realidade global contemporânea -, chegando, antes, a fecundar áreas de estudo limítrofes, como, por exemplo, os assim chamados women and gender studies, onde, fugindo a uma, mais ou menos, análoga lógica histórica de subalternidade cultural, que compara a colonização à alienação linguística da mulher (Godard, 1990, p. 87), o pensamento feminista enquanto pensamento "outro" (isto é, do Outro) vira modelo gnosiológico e sobretudo prática de emancipação política e social.

Neste sentido, muito mais do que as metáforas assimilando o papel subalterno da mulher ao papel subalterno da tradução ou contrapondo, em termos quase biológicos - conforme se lê num estudo pioneiro de Lori Chamberlain (1992) -, o original masculino (produtivo) à tradução feminina (apenas reprodutiva), é principalmente a rejeição das estratégias enunciativas da cultura hegemônica patriarcal, ou melhor, o deslocamento delas para uma linguagem da diferença sexual - segundo escreve Barbara Godard - que faz do discurso de gênero o produto de uma operação tradutiva sui generis. Talvez seja este - por analogia com seu correspondente especular, o famoso cultural turn - um dos exemplos mais emblemáticos do assim chamado Translation turn dos estudos culturais, vale dizer, a apropriação, da parte da crítica dessa área, de uma noção extensiva de tradução enquanto categoria capaz de descrever muitos dos processos de transformação que se registram nas nossas sociedades multiculturais.

Considerada por esse ângulo, então, a história desse entrelaçamento entre cultura e tradução se presta para ser resumida, embora de maneira brutalmente esquemática, nos termos seguintes: de um lado, os teóricos da tradução se têm aproximado das questões da cultura pelo fato de os procedimentos tradutivos se localizarem sempre no interior de contextos sociais, políticos e ideológicos; de outro lado, seguindo o percurso inverso, os Cultural Studies têm chegado à tradução por ser esta uma das chaves de acesso privilegiadas à cultura, entendida como um conjunto de identidades e 
de experiências em contínua negociação. Depreende-se, portanto, que, ao afastar-se de seu tradicional centro de gravidade científico (basicamente de matriz línguístico-literária), disciplinar (coincidinte com os Translation Studies) ou geográfico (o Ocidente, enquanto berço da reflexão tradutológica), a tradução parece se expor a processos de metaforização, que não raro dispensam de qualquer referência à concreta prática interlinguística, absorvida - dir-se-ia - quase por inteiro dentro das novas perspectivas de uma prática fundamentalmente intercultural. Naturalmente, é bem possível, e até desejável, conjugar os desenvolvimentos teóricos mais na moda nesse campo com os aspectos práticos do clássico trabalho textual, tal como fazem, por exemplo, alguns dos estudiosos indianos supracitados, partindo mesmo dos textos traduzidos (quaisquer que sejam: um poema de Tagore ou um obra espiritual da Índia do séc. XII) para elaborar suas interpretações da dialética entre culturas. $\mathrm{Na}$ verdade, porém, tenho a impressão de que estamos assistindo, em particular na Europa e nos Estados Unidos, a um lento, mas cada vez mais inexorável, deslizamento da tradução para as margens da cultura, cujo uso catacrético da nomenclatura tradutória tem levado a uma hibridização conceitual por vezes atordoante, senão francamente abstrusa.

Veja-se, por exemplo, entre muitos outros, o caso emblemático do conceito de tradução cultural, que, posto em circulação pelo guru dos Postcolonial Studies, Homi Bhaba, acaba sendo identificado, no debate contemporâneo, como o paradigma tradutivo por excelência da nossa sociedade globalizada, apesar de estar quase totalmente desvinculado dos pressupostos da prática em que idealmente se inspira, conforme julga - com toda razão - Harish Trivedi. Com efeito, ao contestar esse híbrido terminológico, por ser apenas a expressão de uma condição migrante, ou melhor, "fronteiriça”, e da sua inassimilabilidade (leia-se: intraduzibilidade) a qualquer lógica identitária, no fundo inconciliável com um mundo borderline constantemente em trânsito para confluências transnacionais, Trivedi não se limita a negar qualquer tipo de equivalência entre tradução cultural e tradução de culturas, mas chega 
inclusive a postular que a tradução cultural possa encarnar "the very extinction and erasure of translation as we have always known and practised it" (2007, p. 282). Ora, faço questão de dizer desde já que não concordo com essa conclusão, a qual, evidentemente, assemelha mais a uma provocação do que a uma previsão, assim como, de resto, discordo também de seu corolário, uma vez que o raciocínio de Trivedi aponta para o bilinguismo e o biculturalismo da tradução old-fashioned como sendo a única garantia contra o risco, imanente - no seu entender - à fórmula de Homi Bhaba, de um futuro monolingue e monocultural (o que, diga-se de passagem, vai contudo exatamente na direção oposta àquela imaginada, talvez um tanto utopicamente, pelo célebre autor de The Location of Culture). No entanto, sem redundar no paradoxo - que seria também um exagero - de afirmar que os estudos pós-coloniais estão colonizando os estudos da tradução, nem pregar um anacrônico entrincheiramento disciplinar destes, que iria, afinal, em detrimento do efetivo alcance heurístico daquela interseção metodológica, acho, pelo menos, legítimo observar como o atravessamento dos territórios da cultura não tenha sido sem consequências para a tradução enquanto conceito operacional.

Efetivamente, deste ponto de vista, a consequência principal é, a meu ver, a progressiva diluição de tal conceito de tradução na cultura contemporânea, onde a proliferação de seus significados nem sempre - como vimos - tem sido acompanhada por uma suficiente especialização dos significantes que lhe dizem respeito, a ponto de ser praticamente impossível, hoje em dia, responder sem titubear à pergunta que Douglas Robinson colocava no título de um ensaio de 1997: What is translation $?^{5}$ Não se trata, obviamente, de reivindicar aqui uma absurda noção essencialista do traduzir, em antítese à sua concreta dimensão fenomenológica, a qual determina aliás os modos sociais e contextuais de efetivação dessa prática, conforme as diversas funções por ela assumidas. Nem se trata de dar um juízo de valor sobre tal crescente deriva polissêmica da tradução, afirmando que isso é bom ou ruim: não é isso que me interessa. Muito pelo contrário, o que está sendo implicitamente 
discutido é, antes de mais nada, o papel da tradução - enquanto prática textual, além de metáfora cultural - em um mundo cada vez mais misturado e "líquido", cujas fronteiras culturais se recortam não já entre as diversas sociedades mas sobretudo no interior de cada uma delas, delineando aquele espaço in-between, entre as línguas e as culturas (um verdadeiro entre-lugar), para onde Homi Bhaba, na esteira do conceito de posicionalidade mestiza de Gloria Anzaldúa (1987) ${ }^{6}$, projeta a sua utopia anti-nacionalista da tradução como gesto, simultaneamente político e ético, de negociação da diferença. Esta consciência da contínua relocalização da cultura permitiria, pois, desenvolver perspectivas múltiplas, leituras do $\mathrm{Si}$ e do Outro que põem em xeque não só os conceitos psico-sociais de identidades fixas e de autenticidade, como também as oposições culturais binárias de centro e periferia, de universal e particular, de insider e outsider, acarretando assim a formação de novas identidades "traduzidas", independentes da origem étnica dos sujeitos da tradução e sim relacionadas, ao contrário, com a experiência pessoal deles enquanto indivíduos não pertencentes por completo a nenhum lugar (pense-se no famoso "we are translated men" de Salman Rushdie).

Por conseguinte, levando em conta essa condição pós-colonial de mestiçagem, na qual, para lembrar a citação anterior de Said, estamos todos pascalianamente embarcados, nenhuma língua e nenhuma cultura por si só pode legitimamente aspirar a representar aquela poderosa construção cultural que é a nação, questionando, portanto, também a própria ideia de literatura nacional, uma vez que os textos são hoje muitas vezes o resultado de práticas de escrita autenticamente transnacionais (a gente cresce e pensa em uma língua, escreve em outra e é lida em mais outra língua). E como, nesta fragmentação de línguas e culturas, até a unidade da língua nacional - segundo Naoki Sakai (1992) - é um postulado funcionando "como ideia reguladora" em vez de objeto empírico, isso comporta que, justamente pelo fato de o processo tradutório ter lugar não entre duas línguas, mas no meio delas, isto é, nas fendas abertas dentro das margens fluidas das línguas, "a tradução no 
sentido tradicional (enquanto operação interlinguística) fica, afinal, comprometida". Essa é, pelo menos, a opinião da supracitada Siri Nergaard (2009, p. 510) - uma das mais conceituadas estudiosas da tradução que se encontram hoje na Itália e em cujas reflexões se inspirou uma parte do meu retrospecto inicial -, mas acho que poderia ser bem representativa, em geral, deste tipo de abordagem culturalista.

Isso significa, em suma, que a tradução vai existir no século XXI principalmente como metáfora desse "terceiro espaço", relegando-se aos interstícios das nossas culturas híbridas e portanto cada vez mais desterritorializada, conforme o jargão em moda? Ou não será, ao contrário, que exatamente pelo fato de a sociedade contemporânea se configurar como uma imensa "zona de contato" (na acepção dada ao termo por Pratt (1992, p. 6)), a tradução - entendida desta vez na acepção de produto de um processo, mais do que na do próprio processo - se torna objeto de um investimento simbólico de reterritorialização identitária?

Eis então que entra aqui em jogo a minha proposta de leitura geopolítica da tradução, a qual visa a integrar no debate, ao lado das fascinantes abstrações da teoria pós-moderna e pós-colonial em parte, exercícios de viés futurológico -, a realidade atual dessa prática e de seu estar no mundo, ainda mais em um contexto internacional profundamente mudado, mesmo a respeito de algumas situações com que se havia confrontado a primeira fase dos Cultural Studies (penso, por exemplo, no impasse, para não falar de esvaziamento, do hodierno discurso multiculturalista ou na crise da noção de Ocidente, desaguando inclusive em sua doença senil, o Ocidentalismo, o que se parece também com uma espécie de significativa passagem do bastão em relação ao Orientalismo descrito por Said). E é justamente para esse rearranjo político, ou melhor, geopolítico da globalização que eu gostaria de chamar a atenção agora, a partir daquele aliciante precipitato terminológico que o jornalista francês Jean Daniel (em um artigo publicado em 2010) ${ }^{7}$ tem proposto para denominar a nova época por onde, já faz alguns anos, estamos nos enveredando, vale dizer, "l' ére post-occidentale". Trata-se, como 
se deduz facilmente do prefixo, da época que se vai descortinando, ao mesmo tempo, depois e para além do "fim do Ocidente", isto é, do fim daquele sistema-mundo assente na condição hegemônica (política, econômica, cultural, etc.) da Europa e dos Estados Unidos, cujo eixo civilizacional foi constituindo, ao longo dos séculos, o cerne da nossa modernidade. Desta vez, porém, a referência a tal categoria histórica, mais do que tão-só geográfica, de Ocidente envolve, em particular, uma dimensão justamente espacial, na qual convergem não tanto a spengleriana decadência da ideia do progresso ou a imanente "pós-história" preconizada por Francis Fukuyama, quanto o surgimento de um novo equilíbrio mundial, em que a centralidade cabe agora cada vez mais às velhas periferias do passado, a China, a Índia, o Brasil.

E é, portanto, com vistas a um enquadramento do velho debate teórico sobre a tradução no âmbito deste novo equilíbrio mundial que me parece útil o recurso a um método de análise tal como o da geopolítica, uma disciplina que, após um longo eclipse, a partir da segunda metade do século passado, está gozando agora de renovada popularidade entre os estudiosos europeus e norte-americanos de relações internacionais. Com efeito, sem nos adentrarmos nos complicados meandros da definição de uma disciplina controversa, sobre cuja existência enquanto objeto unívoco de estudo não há ainda consenso unânime na comunidade científica, poderiamos aceitar como conceitos operacionais de geopolítica as seguintes definições: a) o estudo do conjunto das relações internacionais em uma perspectiva espacial e geográfica ${ }^{8}$; b) o estudo das rivalidades de poder sobre territórios disputados entre dois ou mais Estados ou entre grupos políticos ${ }^{9}$. Ora, as duas definições são sem dúvida diferentes, porque evocam imagens diferentes da ordem política (globalização económica vs geopolítica militar), mas não são mutuamente excludentes, sendo até possível considerá-las complementares, uma vez que o processo histórico da mundialização, donde deriva a mais recente globalização da economia, tem se fundado constantemente em uma assimetria de poder entre as várias regiões do planeta. Assim, para aplicarmos esse raciocínio ao assunto da 
tradução, é óbvio que a assunção dessa perspectiva geopolítica não está isenta de repercussões no plano cultural, estando diretamente implicada, por exemplo, na interpretação dos fluxos tradutivos, cuja direção e intensidade corresponde mesmo às relações hierárquicas que se estabelecem entre as línguas conforme o assim chamado modelo gravitacional do linguista francês Louis-Jean Calvet: ou seja, quanto mais uma língua está difundida, tanto mais os textos escritos naquela língua estão sujeitos à tradução.

Mas se a geopolítica das traduções é, desse ponto de vista, uma função da geopolítica das línguas, cuja capacidade de atração decorre, por sua vez, não só do poder político e econômico dos Estados, como também do soft power representado pela cultura, daí - na esteira das reflexões de J. Heilbron ${ }^{10}$ derivam, a meu ver, pelo menos três consequências cruciais: 1) as obras publicadas nos países anglófonos têm mais possibilidades de serem traduzidas para outras línguas, o que se reflete negativamente no grau de diversidade cultural dos polissistemas-alvo; 2) quanto mais uma língua é central no sistema internacional das traduções, menos se traduz para aquela língua, condenando pois o centro do modelo gravitacional de Calvet a ser vítima, paradoxalmente, do mesmo efeito de homogeneização produzido nas suas periferias; 3) para fugir a esse beco sem saída, devo porém acrescentar que um texto tem mais probabilidades de ser traduzido para uma língua periférica se antes for traduzido para uma língua central, o que acaba dando nova seiva aos Estados que gravitam nas áreas linguísticas de maior difusão.

Todavia, sem insistir ulteriormente em um terreno já muito estudado, a partir do ensaio pioneiro de Richard Jacquemond (1992), explicando as desigualdades das trocas tradutivas entre o Norte e o Sul do mundo, como sendo expressão de uma hegemonia cultural que reflete basicamente a hegemonia econômica, faço questão de observar também que a economia não é, porém, o único fator envolvido nas políticas da tradução, conforme, de resto, tem demonstrado um interessantíssimo livro francês de 2009, Les contradictions de la globalisation editorial, (Sapiro, 2009) onde se realça, de modo justamente um tanto contraditório (daí o 
título...), o papel ainda hoje relevante desempenhado, nas trocas culturais globais, pelos Estados-nação. Em outras palavras, apesar de estarmos vivendo em uma fase que poderíamos definir não só pós-ocidental como também “pós-nacional”, quer dizer, na qual é evidente a crise do conceito de nação, ou melhor, da forma de pertencimento nacional, do pertencimento político, cultural, linguístico indicado pelo conceito de nação, no entanto continua sendo palpável a função dos Estados-nação no reconhecimento, por exemplo, de uma concepção nacionalista (intrinsecamente geopolítica) da diferença que preside àquelas práticas de exclusão, subjacentes quer à formação do cânone quer, mais em geral, ao acesso das minorias à literatura. Trata-se de um contraste que, segundo diz Sapiro no volume supramencionado, está no centro das contradições que investem hoje a organização do mercado editorial, as escolhas de tradução e até a materialidade dos atos tradutivos, isto é, o modo como se traduz, levando em conta justamente as novas relações de poder decorrentes do quadro geopolítico da atualidade. Neste sentido, a progressiva desconstrução da ideia do cânone ocidental de bloomiana memória ou, por assim dizer, sua reacomodação em chave pós-ocidental, mais inclusiva e abrangente, não pode se contentar em ser vazada no translationese, aquela "terceira língua" da tradução, assimiladora das diferenças, de que falava Spivak em The politics of translation, mas precisa ser des-hegemonizada mesmo linguisticamente, isto é, em função das estratégias de localização linguística usadas pelas literaturas pós-coloniais como projeto político-cultural.

Se, com efeito, o diverso estatuto social das línguas coloniais, que permaneceram, na maioria dos casos, como línguas oficiais da geografia da descolonização, acaba convertendo seu uso da parte dos aloglotas nativos em uma implícita opção de viés político, é sobretudo o processo de indigenização dessas línguas, quer dizer, a reconfiguração local dos padrões europeus, que assume uma conotação patentemente subversiva, enquanto típico exemplo de apropriação anti-hegemônica e até resistencial dos códigos alheios, abrindo espaço para a diferença no interior de uma enunciação 
aparentemente monolinguística. Daí que o texto pós-colonial, com seus desvios em relação às normas eurocêntricas, vai se tornando uma espécie de território disputado entre o neocolonialismo linguístico das antigas metrópoles (através de suas ramificações institucionalizadas em entidades supranacionais: a francofonia, a anglo-esfera, a lusofonia, etc.) e os direitos de autorepresentação, inclusive cultural, dos novos países independentes. Aliás, levando em conta que para muitos escritores pós-coloniais o mesmo ato da escrita nessas línguas não maternas é considerado já por si uma tradução, cabe então aos tradutores desses textos, não só na passagem de uma língua colonial para outra, a tarefa de manter a tensão existente no original entre a koiné e o vernáculo, entre a língua de superfície e a língua subjacente, sem se deixarem tentar por propósitos de recolonização cultural.

Segundo escreve Paul Bandia a respeito da literatura africana nas línguas europeias - mas o discurso se presta para ser aplicado com sucesso também a outros contextos - "não obstante o texto euro-africano possa subverter o domínio do discurso colonial do Ocidente sobre aquele tradicional da África, a sua tradução para outra língua europeia pode anular aquela força subversiva por meio das estruturas de domínio que estão contidas em cada língua" (Bandia, 2009, p. 346)

Isso significa, portanto, que, longe de ser apenas uma bela metáfora para perspectivar as dinâmicas do mundo editorial contemporâneo, a geopolítica entendida como questão inerente às rivalidades territoriais, não pode não afetar também aquelas zonas de contato por excelência que são as traduções, onde os supostos encontros entre culturas adquirem não raro as feições de embates entre modelos culturais conflitantes. Não estou me referindo tão-só àquelas "zonas tradutivas" de guerra, conforme as define Emily Apter em um célebre ensaio, ou seja, em que "as linhas de fronteira entre as línguas se tornam confusas e objeto de disputa" (2009, p. 360), como também a todo e qualquer encontro linguístico mediado pela tradução, a qual - diferentemente do lugar comum, que a descreve como uma ponte entre culturas - é sempre 
uma operação violenta ou que traz em si os rastros da violência exercida por uma cultura sobre a outra. De fato, além da violência, que, no entender de Venuti (1993, pp. 209), reside no próprio processo tradutório, levando à substituição das diferenças linguísticas e culturais do texto estrangeiro por um texto condizente com os valores, as crenças e as representações da cultura de chegada, a violência está inscrita no próprio texto traduzido, sendo simultaneamente a causa e o efeito daquela demarcação de fronteiras em que consiste, no final das contas, a tradução. Assim, demarcando os limites das culturas de fora no interior da nossa cultura, ou delimitando o espaço das culturas de dentro a respeito da cultura oficial ou ainda incorporando essas fronteiras à língua traduzente (pense-se, por exemplo, no hibridismo das línguas das traduções, mais ou menos acentuado, dependendo do prestígio da língua fonte e da língua alvo), a tradução parece agir com base em categorias da ordem exatamente geopolítica, refletindo as relações de poder assimétricas da atualidade. Sob esse aspecto, o inglês chinesizado das autotraduções chinesas da literatura autóctone (cf. Hung, 2009) ou o italiano anglicizado das traduções de obras anglófonas são enfim as duas faces da mesma moeda geopolítica com que se pagam hoje em dia as trocas culturais planetárias. Por isso, em comparação com as teorias pós-coloniais do terceiro espaço e da hibridização das culturas, uma leitura geopolítica da tradução, na minha opinião, pode dar conta também daquele resíduo intransponível que sempre permanece - seja qual for - nas margens do contato intercultural, fazendo, no fundo, da relação entre cultura e tradução uma experiência substancialmente aporética, ou melhor, paradoxal, conforme nos lembram essas palavras emblemáticas de Sherry Simon (1992, p. 159): "simbolically, translation comes to be the very representation of the play of equivalence and difference in cultural interchange: translation permits communication without eliminating the grounds of specificity."

Talvez seja com este paradoxo da tradução - independentemente das nossas abordagens individuais - que devemos aprender a lidar, ainda hoje, no século XXI. 


\section{Notas}

1. Cf. "Translation, Colonialism and Poetics: Rabindranath Tagore in Two Worlds" in Bassnett-Lefevere, 1990, pp. 56-63.

2. Cf. "Theorizing Feminist Discourse/Translation" in Bassnett-Lefevere 1990, pp. 87-96.

3. A tradução para português destas citações do ensaio de Trivedi é minha.

4. Refiro-me a A. Dingwaney - C. Maier (eds.), Between Languages and Cultures. Translation and Cross-Cultural Texts, Pittsburgh, University of Pittsburgh Press, 1995

5. What is Translation? Centrifugal Theories, Critical Interventions, Kent, The Kent State University Press, 1997.

6. Borderlands/La frontera, San Francisco, Aunt Lute, 1987.

7. Le Nouvel Observateur, 18 de agosto de 2010.

8. Cf. Geoffrey Parker, The Geopolitics of Dominance, London, Routledge, 1998

9. Cf. Yves Lacoste, Geopolitique, la longue histoire d'aujourd'hui, Paris, Larousse, 2006.

10. Cf. "Towards a sociology of translations: book translations as a cultural world-system" in European Journal of Social Theory, 2-1999, pp. 429-444). 


\section{Referências}

APTER, Emily. Babele balcanica: zone traduttive, zone militari. Trad. di R. Merlini. In: Bollettieri Bosinelli R. M; Di Giovanni E. (Org.). Oltre l'Occidente. Traduzione e alterità culturale. Milano: Bompiani, 2009. p. 355-382.

BANDIA, Paul. Alcune considerazioni etiche sulla letteratura africana nelle lingue europee e sulla scrittura come traduzione. Trad. di F. Gaspari. In: Bollettieri Bosinelli; Di Giovanni (Org.). 2009. p. 325-351.

BASSNETT , Susan; LEFEVERE, Andre. (Ed.). Translation, History \& Culture. London and New York: Pinter Publishers, 1990.

BASSNETT , Susan; TRIVEDI, Harish. (Ed.). Postcolonial Translation. Theory and Practice. London and New York: Routledge, 1999.

CATFORD, John C.. Uma teoria linguística da tradução: um ensaio de linguística aplicada. São Paulo: Cultrix, 1980.

CHAMBERLAIN, Lori. Gender and the Metaphorics of Translation. In: Venuti, Lawrence (Ed.). Rethinking Translation. Discourse, Subjectivity, Ideology. London and New York: Routledge, 1992. p. 57-74.

DEMARIA, Cristina. Figure e strategie dell'identità postcoloniale. In: Bianchi, C; Demaria, C; Nergaard, S. (Org.). Spettri del Potere. Ideologia, identità, traduzione negli studi culturali. Roma: Meltemi Editore, 2002. p. 119-127.

GODDARD, Barbara. Theorizing Feminist Discourse/Translation. In: Bassnett, S; Lefevere, A. (Ed.). Translation, History \& Culture. London and New York: Pinter Publishers, 1990.p. 87-96.

HUNG, Eva. La traduzione collaborativa, ovvero ciò che possiamo imparare dalla tradizione traduttiva cinese. Trad. di L. Cirillo. In: Bollettieri Bosinelli; Di Giovanni (Ed.). 2009. p. 81-110. 
JACQUEMOND, Richard. Translation and Cultural Hegemony: the Case of French-Arabic Translation. In: Venuti, Lawrence (Ed.). 1992. p. 139-158.

LEFEVERE, André. Traduzione e riscrittura. La manipolazione della fama letteraria. Trad. di S. Campanini. Torino: UTET, 1998.

MARTINS, Marcia A.P. O papel da patronagem na difusão da literatura brasileira: o programa de apoio à tradução da Biblioteca Nacional. In: Guerini, A; Torres, M.H; Costa, W.(Ed.). Literatura Traduzida e Literatura Nacional. Rio de Janeiro: 7Letras, 2008. p. 39-52.

NERGAARD, Siri. Cosa significa traduzione oggi?. In: Bollettieri Bosinelli; Di Giovanni (Ed.). 2009. p. 479-518.

NIRANJANA, Tejaswini. Siting Translation: History, Poststructuralism and the Colonial Context. Berkeley: University of California Press, 1992.

PADUANO, Guido. Tradurre. In: Lavagetto, Mario (Ed.). Il testo letterario. Istruzioni per l'uso. Roma-Bari: Laterza, 2004. p. 133-152.

PRATT, Mary Louise. Imperial Eyes: Travel Writing and Transculturation. London and New York: Routledge, 1992.

SAKAI, Naoki. Voices of the Past. The Status of Language in Eighteen-Century Japanese Discourse. New York: Cornell University Press, 1992.

SAPIRO, Gisèle (Org.). Les contradictions de la globalisation editoriale. Paris: Nouveau Monde, 2009.

SIMON, Sherry. The language of Cultural Difference: Figures of Alterity in Canadian Translation. In: Venuti, Lawrence (Ed.). 1992. p. 159-176.

SPIVAK, Gayatri. Can the Subaltern Speak?. In: Nelson, C; Grossberg, L. (Ed.). Marxism and the Interpretation of Culture. Urbana: University of Illinois Press, 1988. p. 271-313. 
TRIVEDI, Harish. Translating Culture vs Cultural Translation. In: St-Pierre, P.; Kar P.C. (Ed.). In: Translation - Reflections, Refractions, Transformations. Amsterdam: John Benjamins, 2007. p. 277-287.

TRIVEDI, Harish. Costruire l'Oriente: traduzioni inglesi dall'India nel XIX secolo. Trad. di C. Vestito. In: Bollettieri Bosinelli, R. M; Di Giovanni E. (Org.). Oltre l'Occidente. Traduzione e alterità culturale. Milano: Bompiani, 2009. p. 149-181.

VENUTI, Lawrence. Translation as Cultural Politics: Regimes of Domestication in English. In: Textual Practice, vol. 7/2, 1993. p. 208-223.

VENUTI, Lawrence. La formazione delle identità culturali. Trad. di C. Bianchi e S. Nergaard. In: Bianchi-Demaria-Nergaard (Ed.). 2002. p. 195-229.

Recebido em: 16/12/2014

Aceito em: 26/02/2015 